\title{
Orientation Selectivity without Orientation Maps in Visual Cortex of a Highly Visual Mammal
}

\author{
Stephen D. Van Hooser, ${ }^{1 \star}$ J. Alexander F. Heimel, ${ }^{1 *}$ Sooyoung Chung, ${ }^{1}$ Sacha B. Nelson, ${ }^{1}$ and Louis J. Toth ${ }^{2}$ \\ ${ }^{1}$ Brandeis University, Waltham, Massachusetts 02454, and ${ }^{2}$ Boston University, Boston, Massachusetts 02188
}

In mammalian neocortex, the orderly arrangement of columns of neurons is thought to be a fundamental organizing principle. In primary visual cortex (V1), neurons respond preferentially to bars of a particular orientation, and, in many mammals, these orientationselective cells are arranged in a semiregular, smoothly varying map across the cortical surface. Curiously, orientation maps have not been found in rodents or lagomorphs. To explore whether this lack of organization in previously studied rodents could be attributable to low visual acuity, poorly differentiated visual brain areas, or small absolute V1 size, we examined V1 organization of a larger, highly visual rodent, the gray squirrel. Using intrinsic signal optical imaging and single-cell recordings, we found no evidence of an orientation map, suggesting that formation of orientation maps depends on mechanisms not found in rodents. We did find robust orientation tuning of single cells, and this tuning was invariant to stimulus contrast. Therefore, it seems unlikely that orientation maps are important for orientation tuning or its contrast invariance in V1. In vertical electrode penetrations, we found little evidence for columnar organization of orientation-selective neurons and little evidence for local anisotropy of orientation preferences. We conclude that an orderly and columnar arrangement of functional response properties is not a universal characteristic of cortical architecture.

Key words: orientation; functional map; columns; primary visual cortex; V1; gray squirrel; rodent

\section{Introduction}

A central feature of many areas within the mammalian neocortex is the orderly arrangement of columns of neurons, termed functional architecture (Hubel and Wiesel, 1962). Neurons below a single position on the cortical surface have remarkably similar receptive field properties, and these properties generally change smoothly as one travels along the surface. This organization has been described in many cortical areas, including visual, auditory, somatosensory, and prefrontal cortex (Mountcastle, 1997), and is thought to be important for information processing by facilitating connections among neurons with similar properties (BenYishai et al., 1995; Somers et al., 1995). In primary visual cortex (V1), neurons respond preferentially to images of bars or edges of a particular orientation, and, in V1 of primates (Hubel et al., 1978; Blasdel and Salama, 1986), carnivores (Hubel and Wiesel, 1963; Grinvald et al., 1986; McConnell and LeVay, 1986), ungulates (Clarke et al., 1976), and tree shrews (Humphrey and Norton, 1980; Bosking et al., 1997), these orientation-selective cells are arranged in a semiregular, smoothly varying map with local discontinuities. Curiously, whereas electrophysiological and imaging studies of many rodents, including mice (Metin et al., 1988; Schuett et a., 2002), rats (Girman et al., 1999), hamsters (Tiao and

\footnotetext{
Received March 8, 2004; revised Nov. 10, 2004; accepted Nov. 10, 2004.

We gratefully acknowledge the National Institutes of Health (NS032137, NS033975, NS046881), the National Eye Institute (EY11116), the Sloan-Schwartz Foundation, and the late Bertram Payne for providing support and equipment, and we thank Justine Barry and Keow Essig for histology.

*S.D.V.H. and J.A.F.H contributed equally to this work.

Correspondence should be addressed to Stephen D. Van Hooser, Brandeis University, 415 South Street, Waltham, MA 02454. E-mail: vanhoosr@brandeis.edu.

DOI:10.1523/JNEUROSCI.4042-04.2005

Copyright $\odot 2005$ Society for Neuroscience $\quad$ 0270-6474/05/250019-10\$15.00/0
}

Blakemore, 1976), and a lagomorph, the rabbit (Murphy and Berman, 1979), have identified orientation-selective neurons in these species, no orderly orientation map has been found. Understanding why these animals do not have orientation maps may shed light on functional roles and developmental mechanisms of orderly maps in mammalian sensory cortex.

Previously examined rodents do not rely heavily on vision and not only lack orientation maps but also do not have the acuity and contrast sensitivity of primates, carnivores, and tree shrews, and have poorly laminated visual brain structures such as lateral geniculate nucleus (LGN) and V1. Perhaps these features are all hallmarks of a highly derived mammalian visual system that go hand in hand. Alternatively, all mammals might possess the necessary mechanisms to develop orientation maps, but maps might not form in animals with small absolute V1 size. Orientation maps in large animals might facilitate connections among neurons with similar orientation preferences but might not be necessary in small animals, because these connections might form easily without local grouping. Finally, rodents and lagomorphs may simply have a different system of organization in area V1.

To examine these ideas, we studied orientation selectivity in V1 of a highly visual rodent, the gray squirrel. Squirrels have high acuity and contrast sensitivity (Jacobs et al., 1982), comparable with tree shrews (Petry et al., 1984), and possess a highly elaborated visual system with a large and well-laminated LGN and V1 (Hall et al., 1971; Van Hooser et al., 2003). V1 in squirrel is much larger than in other studied rodents, being $\sim 10$ times as large as in rat. Importantly, it is also larger than in tree shrew and comparable with mink and ferret, which possess orientation maps.

Using intrinsic signal optical imaging and single-unit recording, we found no evidence of orientation maps in squirrel similar 
to those observed in primates, carnivores, and tree shrews. We did find robust orientation tuning in single-unit recordings and strong activation of visual cortex with oriented stimuli in our imaging experiments. These results suggest that neither good acuity and well-laminated visual brain structures nor large absolute $\mathrm{V} 1$ area is sufficient for the formation of an orientation map, and that an orientation map is not essential for strong orientation tuning. We suggest that an orderly arrangement of functional properties is not a universal characteristic of cortical architecture.

\section{Materials and Methods}

Surgery. We prepared wild gray squirrels, Sciurus carolinensis, following methods described previously (Van Hooser et al., 2003). In brief, animals were initially anesthetized with ketamine and acepromazine maleate (90 $\mathrm{mg} / \mathrm{ml}$ ketamine, $0.91 \mathrm{mg} / \mathrm{ml}$ acepromazine maleate, $0.5 \mathrm{ml} / \mathrm{kg}$ initial dose, i.m.), followed by either urethane $(0.1 \mathrm{gm} / \mathrm{ml}$ urethane, $5 \mathrm{ml} / \mathrm{kg}$, i.p.) or, in most single-unit recording experiments, isoflurane gas (0.5$2 \%$ ). Consistent with other reports in rodents (Schuett et al. 2002), we found urethane to be more effective than halothane for obtaining stable intrinsic imaging recordings. Each animal was positioned in a stereotaxic device so that the roof of the mouth was parallel to the ground, and measurements of visual angle were made from an imaginary line extending anterior from the nose in the same plane as the roof of the mouth. Animals were paralyzed with gallamine triethiodide $(10 \mathrm{mg} / \mathrm{ml}, 0.5 \mathrm{ml} /$ hr, i.v.), and we took care to monitor the heart rate and EEG to ensure adequate anesthesia, giving additional urethane if spindle activity disappeared on the EEG or if the heart rate increased in response to a toe pinch. All procedures were approved by the animal care and use committees at Brandeis University and Boston University.

In imaging experiments, a craniotomy was performed above the primary visual cortex, $\sim 2-7 \mathrm{~mm}$ lateral from bregma and $6-13 \mathrm{~mm}$ posterior to bregma, the dura resected, and a metal chamber with a glass top was secured over the craniotomy with dental acrylic and filled with oil. We found craniotomy and dura resection necessary for imaging because the dura mater in squirrels is often pigmented, which complicates imaging through thinned skull and dura mater as is common in other small animals (Bosking et al., 1997; Schuett et al., 2002). Smaller craniotomies were made in physiology experiments than in imaging experiments, and, in most experiments, the dura was left intact.

Imaging. Primary visual cortex in squirrel is dorsal and posterior (see Fig. 1). The cortex is divided into a medial monocular zone that receives strictly contralateral input and a lateral binocular zone, mediating $30^{\circ}$ per hemisphere in squirrels, that receives input from both eyes (Hall et al., 1971). We generally imaged the contralateral hemifield in the binocular region from $\sim 0-45^{\circ}$ nasal-temporal and from -18.5 to $18.5^{\circ}$ inferiorsuperior (see Fig. 1a), which corresponds to the area of maximum representation in V1 (Hall et al., 1971). In imaging experiments, we verified that we were recording in $\mathrm{V} 1$ by observing the shape of the brain and receptive field structure. In V1, receptive fields move from temporal to nasal as one moves medially to laterally on the brain surface. Receptive field mapping, studies of cytoarchitecture, and studies of connections from the thalamus (Hall et al., 1971; Kaas et al., 1972) have shown that squirrel V1 extends beyond the medial edge of each hemisphere and folds underneath, and area V3, the only neighboring area with receptive fields that move nasally as one moves laterally, is not located on the flat dorsal surface of the brain but is on the temporal slope. We did not perform histology in imaging experiments.

Our Imager 3001 imaging system was developed by Optical Imaging (Rehovot, Israel). To image, we positioned a Teli CS8310 camera so that the surface blood vessels were as parallel to the camera as possible and in focus and then focused $400-600 \mu \mathrm{m}$ below this point. Stimuli were generated on a Pentium II computer with a Visual Stimulus Generator board (Cambridge Research Systems, Kent, UK) and a Mitsubishi Diamond Pro 2060u monitor. For recording, 5-10 frames of data (600 msec/ frames) were acquired under $605 \mathrm{~nm}$ light using a Genesis frame grabber on a Pentium computer. Retinotopy stimuli were drifting gratings [spatial frequency, 0.2 cycles per degree (cpd)] that randomly changed orientations each $300-600 \mathrm{msec}$ in one of six rectangles $\left(18.5 \times 15^{\circ}\right)$ on the screen. The location of the rectangle was pseudorandomly varied over six locations (see Fig. $2 a$ ), and the responses at each location were averaged over 10-26 trials. Orientation stimuli were full-screen drifting gratings shown at $0,45,90$, or $135^{\circ}$, and both directions were used. The spatial frequency of the gratings for the majority of recordings was $0.2 \mathrm{cpd}$, which we found to drive a vast majority of cortical neurons in single-unit recordings, although we tried a range of spatial frequencies from $0.1-0.8$ cpd. Stimuli were pseudorandomly varied, and 26 trials were recorded. Stimuli lasted $\sim 2 \mathrm{sec}$ in both cases, and, in both cases, the interstimulus interval was $\sim 4-5 \mathrm{sec}$.

Data were analyzed in custom software written in Matlab (MathWorks, Natick, MA). Each stimulus response was normalized by subtracting the response recorded during the first frame at each pixel. Blood vessel pixels and out-of-focus pixels were removed from additional consideration by computing the SD across stimuli for each pixel and excluding pixels with extremely high (blood vessels) or extremely low (out of focus) variation (see supplemental Fig. 2, available at www.jneurosci.org as supplemental material). Individual pixel responses were generally not normally distributed (Kolmogorov-Smirnov test), so the nonparametric Kruskal-Wallis test was used for statistical comparisons across stimuli, and the bootstrap method (Press et al., 1993) was used to generate simulated data for studying the resolution limits of our recordings (see Fig. $4 c$ ).

The two cats used in Figures 3 and 4 were anesthetized with halothane, $4 \%$ induction and $1-1.5 \%$ maintenance, and paralyzed with gallamine triethiodide $(10 \mathrm{mg} / \mathrm{kg} / \mathrm{hr})$. Cats were intubated and artificially respired in $70 / 30$ mixture of $\mathrm{N}_{2} \mathrm{O} / \mathrm{O}_{2}$. End-tidal $\mathrm{CO}_{2}$ was maintained at $4 \%$. Bilateral craniotomy and durotomy was centered at Horsley-Clark A3, allowing access to superficial area 18 (V2). Atropine sulfate and phenylephrine hydrochloride eye drops were used to dilate pupils and retract the nictitating membrane. Eyes were focused using appropriate contact lenses. Stimuli were identical to those used in squirrel.

Single-unit recordings. We recorded single units in V1 with $10 \mathrm{M} \Omega$ microelectrodes (Frederick Haer Company, Bowdoinham, ME). We recorded 221 neurons under isoflurane anesthesia and 43 neurons under urethane anesthesia. Twenty-eight of these neurons had peak firing rates lower than $3 \mathrm{~Hz}$ or did not respond to visual stimuli and were excluded from additional analysis. Receptive field locations for these neurons overlapped the area studied in the imaging analysis. Single units had receptive fields located between -5 and $70^{\circ}$ horizontally and between 5 and $-30^{\circ}$ vertically, although most units had receptive fields within $35^{\circ}$ horizontally. We used the same criteria for identifying $\mathrm{V} 1$ as in imaging studies and, in addition, looked for brisk responses in layer IV with a low-impedance electrode $(0.1 \mathrm{M} \Omega)$. Electrode locations were verified histologically (see Fig. $1 c, d$ ). Electrodes were coated with diI (Snodderly and Gur, 1995). After the experiment, the animal was given a large dose of ketamine-acepromazine and transcardially perfused with $0.1 \mathrm{M}$ PBS followed by $4 \%$ paraformaldehyde. Sections were flash frozen in a slurry of dry ice and isopentane $\left(-20^{\circ} \mathrm{C}\right)$ for $30 \mathrm{sec}$, and $50 \mu \mathrm{m}$ sections were cut on a cryostat. Sections were photographed to visualize diI before Nissl staining. Nissl staining was accomplished by drying slices in a $55^{\circ} \mathrm{C}$ oven overnight, followed by dehydration in successive stages of $25,50,75,95$, 100 , and $100 \%$ ethanol for $15 \mathrm{~min}$ each, two washes in xylenes for $15 \mathrm{~min}$ each, and rehydration in 100, 100, 95, 70, 50, and 0\% ethanol for $15 \mathrm{~min}$ each. Sections were then stained with cresyl violet for $40 \mathrm{~min}$, differentiated in 70\% ethanol for $30 \mathrm{sec}$, washed in xylenes for $1 \mathrm{~min}$, and coverslipped with DPX (a mixture of distyrene, tricresyl phosphate, and xylene) mounting medium. We identified V1 by its cytoarchitecture following Hall et al. (1971) and Kaas et al. (1972), and in every case the electrode was found to be in V1.

Stimuli were shown on a cathode ray tube (Samsung 900SL; Samsung, Irvine, CA) with a refresh rate of $120 \mathrm{~Hz}$ connected to a Macintosh G4 running custom software written in Matlab using the Psychophysics Toolbox (Brainard, 1997; Pelli, 1997). Data were analyzed with custom software written in Matlab. We measured responses to drifting sinusoidal gratings of 12-16 directions, pseudorandomly varied with an interstimulus interval of $3 \mathrm{sec}$. Responses and orientation indices were computed using the mean firing rate minus the spontaneous rate. This seemed most natural for comparison with intrinsic imaging measurements, where the first frame is subtracted when computing the response. To measure orien- 


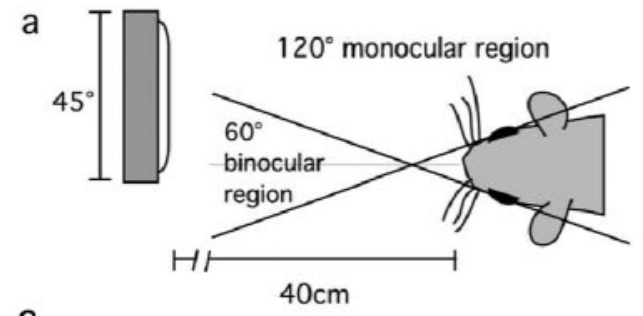

C

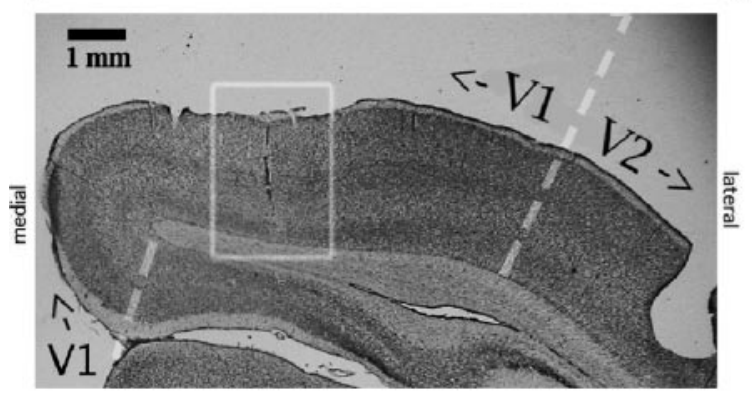

b

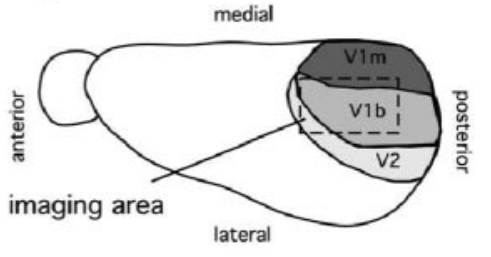

d

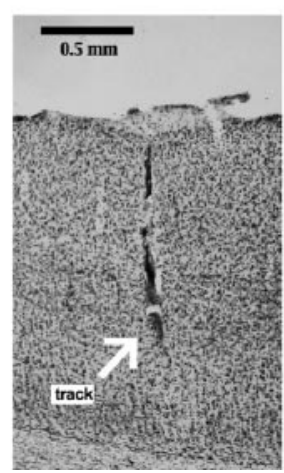

Figure 1. Intrinsic imaging and single-unit recording in primary visual cortex in squirrel. $a$, Imaging stimuli were presented on a monitor positioned to cover the binocular visual field, which is $\sim 30^{\circ}$ per hemifield in squirrel. $b$, Intrinsic images were recorded in the contralateral primary visual cortex in the region indicated by the dotted rectangle. V1b, Binocular V1; V1m, monocular V1. c, Nissl section showing a microelectrode track in V1. V1 can be distinguished from V2 by the distinct and thick layer IV in V1. $d$, Close-up of the electrode track.

a

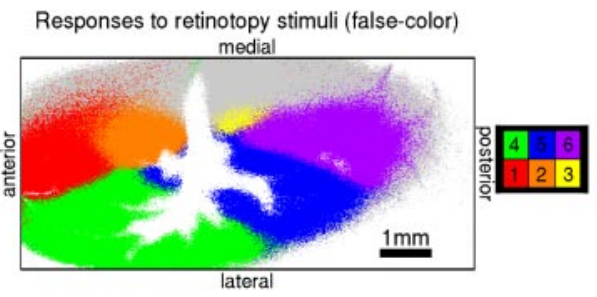

b

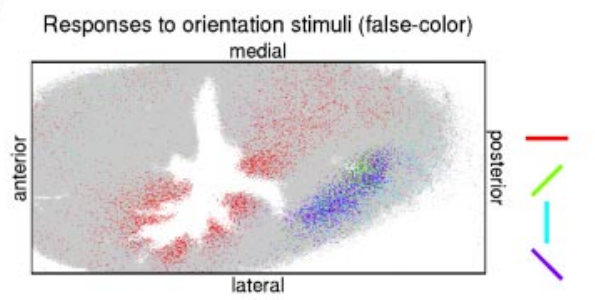

C

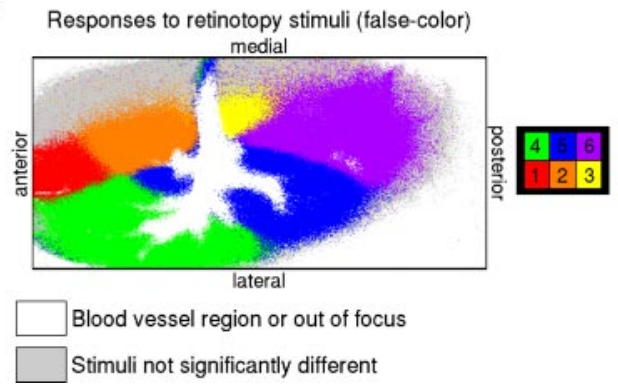

Mean responses to individual stimuli
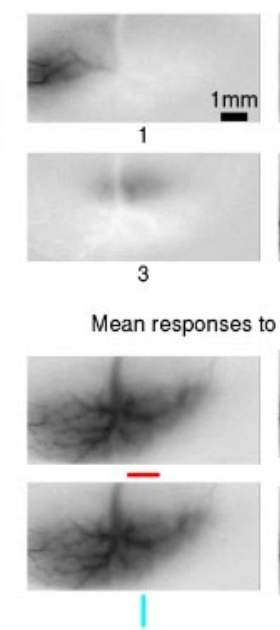

Mean responses to individual stimuli

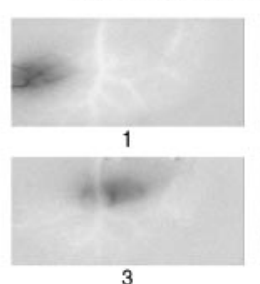

3
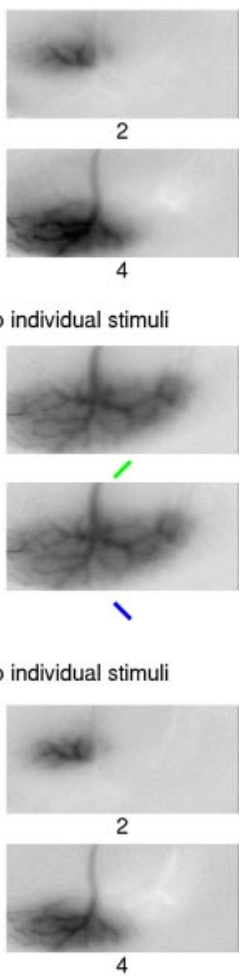

Figure 2. Intrinsic imaging reveals strong retinotopic organization but no spatial organization of orientation preference. $a$, Left, False-color image of responses to gratings of randomly varied orientation at six locations in the visual field, diagrammed in the middle. Pixels that show significantly different $(p<0.05)$ activity across stimuli are shown in color, whereas insignificant pixels are gray. Regions where the SD of the signal was particularly high (blood vessels) or low (out of focus) have been excluded and colored white. Right, Individual average responses for four stimuli. $b$, Left, False-color image of responses to full-screen gratings of different orientation, shown at the middle. Very few pixels show significantly different activation across stimuli, despite strong mean activation to individual stimuli, shown at the right. Data were recorded immediately after that in $a . c$, Responses to same retinotopy stimuli as in $a$, recorded immediately after those in $b$, indicating maintained good hemodynamic signals.

tation-tuning width, we computed the halfwidth at half-maximum response height (HWHH). For this measurement, the spontaneous rate was not subtracted.

\section{Results}

Imaging responses to retinotopy and orientation stimuli

Using optical imaging of intrinsic signals, we assessed the spatial organization of orientation selectivity in primary visual cortex of six squirrels (Fig. 1). We initially obtained a retinotopic map by showing drifting gratings of variable orientation in rectangular patches at six locations (Fig. $2 a)$. The existence of a well-defined map and good response time course (Fig. 3a) were taken to indicate a healthy visual cortex with good hemodynamic responses. After obtaining a retinotopic map, we showed sinusoidal gratings at four different orientations on the whole screen. Finally, we obtained another retinotopic map to demonstrate the continued presence of a hemodynamic response throughout the recording session. Recording responses to these stimuli took $\sim 90 \mathrm{~min}$.

Responses to one such experiment are shown in Figure 2. Figure $2 a$ shows a retinotopic map in response to the initial retinotopy stimuli. The map is evident in both the average responses to individual stimuli and a false-color image that shows which stimulus was maximal for each pixel showing significantly different activity across stimuli (nonparametric Kruskal-Wallis test; $p<0.05)$. A similar false-color map and average responses to individual orientation stimuli are shown in Figure $2 b$. There is clearly a large response to each of the individual orientation stimuli, but the responses are all very similar, and there are only a few pixels that show significant differences across the different stimuli in the false-color image. No orientation map similar to those observed in tree shrews (Humphrey and Norton, 1980; Bosking et al., 1997), monkeys (Hubel el. al, 1978; Blasdel and Salama, 1986), and cats (Hubel and Wiesel, 1963; Grinvald et al., 1986) is apparent in either the false-color map or the individual responses. Finally, responses to a subsequent presentation of the retinotopy stimuli (Fig. $2 c$ ) are very similar to those of the initial retinotopy recordings, suggesting there were no problems with the brain or hemodynamic signals during the orientation stimulation.

Response intensity and time course were very similar for both retinotopic and orientation stimuli. Figure $3 a$ shows the average response intensity as a function of poststimulus time for two $10 \times 10$ pixel 
regions for the same data shown in Figure 2 . The response time course is very similar for both stimuli, but the responses to retinotopy stimuli show much greater variation across stimuli than the responses to the orientation stimuli, which are all very similar. Figure $3 b$ shows the normalized mean response intensity for retinotopic and orientation stimuli, computed for each pixel as the mean response to the stimulus that activated the pixel maximally and normalized to the mean of the retinotopy responses. The normalized response intensity is very similar for retinotopy and orientation stimuli, and the differences are not significant $(t$ test; $p=$ $0.90)$, suggesting that both types of stimuli are approximately equally effective in activating the cortex.

We examined the fraction of pixels that were differentially activated by different stimuli for retinotopy and orientation stimuli quantitatively. The fraction of pixels showing very significantly different activation for both types of stimuli (KruskalWallis test; $p<0.001$ ) is shown in Figure $3 b$. On average, $32.7 \%$ of all pixels showed very significant differences across different retinotopy stimuli, whereas only $1.4 \%$ of all pixels showed very significant differences across different orientation stimuli, and this difference is highly significant $(t$ test; $p<0.001)$. The fraction of pixels that show significant differences across orientation stimuli with a significance level of 0.001 is not statistically different from what one would expect by chance from purely randomly generated data ( $t$ test; $p=0.15)$. To compare the responses in squirrel with responses observed in other animals, we collected data from V2 in two cats that were being used in other experiments. We recorded responses to the same full-screen grating stimulus used above and observed a robust orientation map (Fig. 4). We calculated the percentage of very significantly different $(p<0.001)$ pixels across these two stimuli and obtained a value of $14.6 \%$. This number was significantly higher than the value for squirrel ( $t$ test; $p<0.001$ ).

We also examined periodicity in the mean responses to orientation stimuli in $\mathrm{V} 1$ of the four squirrels and V2 of the two cats using Fourier analysis. Figure 4 shows mean responses to orientation stimuli in two squirrels and one cat; each pixel is colored to indicate the stimulus that evoked the maximum response, and the significance of the differences across stimuli is ignored in this analysis. Although no maps are evident in the squirrel responses, a robust map is evident in the cat responses. a
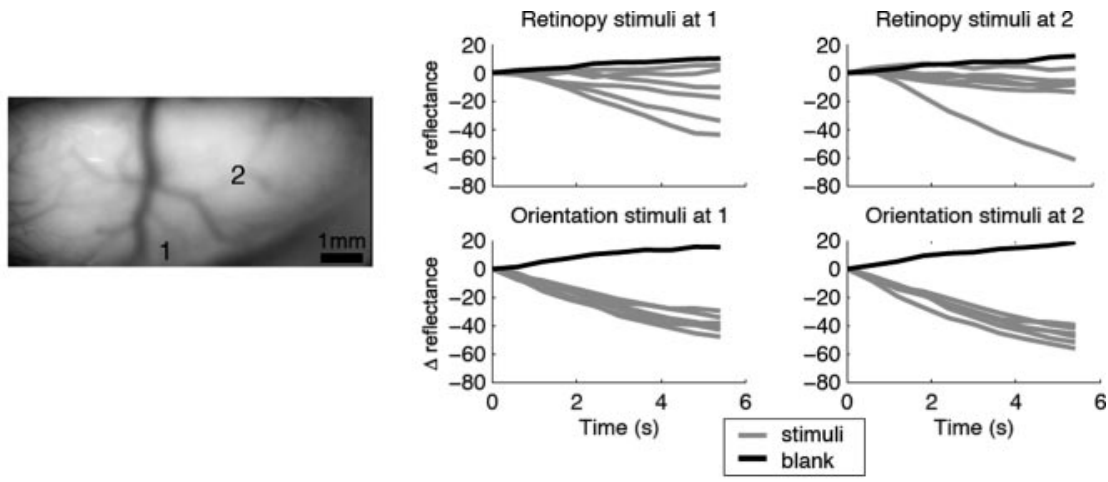

b
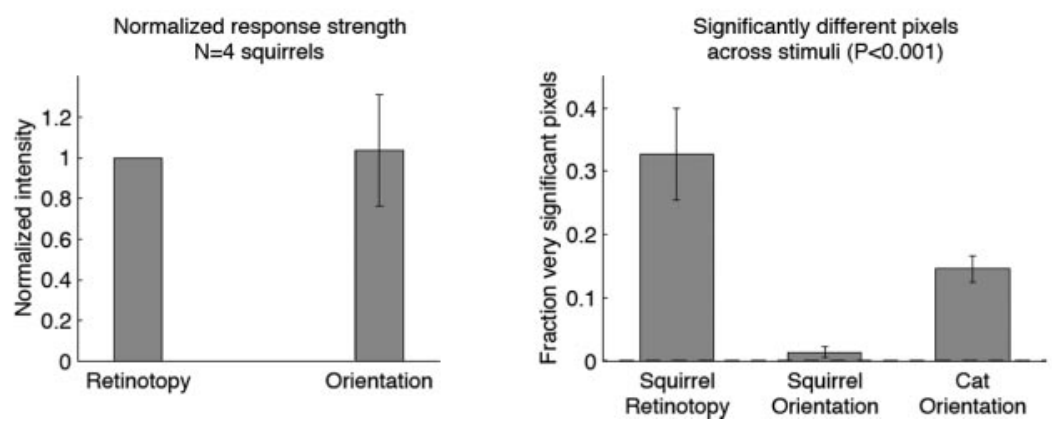

Figure 3. V1 responses to gratings of different orientation stimuli are strong but are spatially similar. $a$, Left, Photograph of the same brain as Figure 2 . Regions 1 and 2 are $10 \times 10$ pixels in size. Right, Mean responses in regions 1 and 2 to individual retinotopic stimuli (top) and orientation stimuli (bottom) shown in gray, with responses during blank trials in black. Note that although the responses have similar intensities (signal is negative) and time courses, there is much less deviation across the responses to orientation stimuli than responses to retinotopy stimuli. $b$, Left, Strength of response to retinotopy stimuli and orientation stimuli, normalized to the retinotopy stimulus response. Both stimulus types produce responses of approximately equal intensity. Right, Fraction of pixels that show very significant $(p<0.001)$ differences in activation across stimuli for retinotopy and orientation stimuli in four squirrels and orientation stimuli in two cats. A substantial number of pixels show differences for retinotopy stimuli in squirrel but few pixels show differences for orientation stimuli. A larger fraction of pixels show differences for orientation stimuli in cat. Error bars indicate SES.
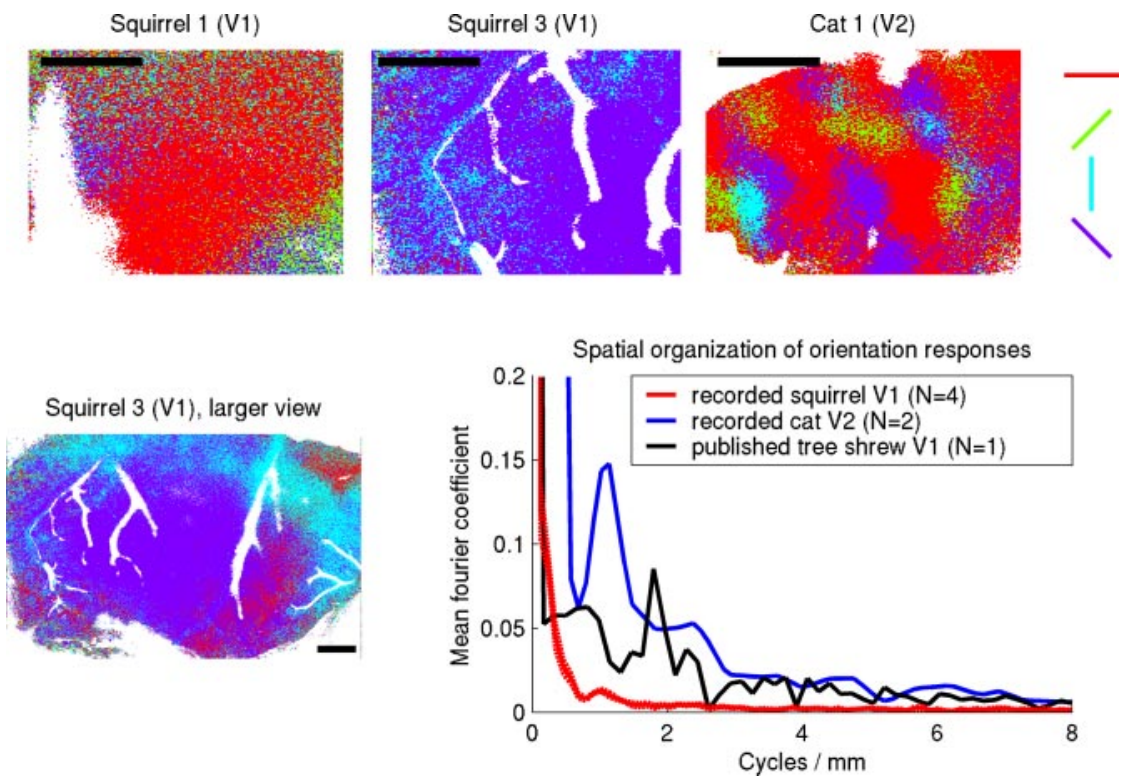

Figure 4. Periodicity in mean orientation responses for recorded squirrel V1, recorded cat V2, and published tree shrew from Bosking et al. (1997). Scale bars, $1 \mathrm{~mm}$. Top, Winner-take-all maps indicating which stimulus was maximal at each pixel for two squirrels and one cat. Significance of differences across stimuli is ignored in this analysis. No map is evident in squirrel responses, but a clear orientation map is apparent in cat V2. Bottom left, Larger view of squirrel 3 responses. Bottom right, Spatial organization of orientation responses determined by mean absolute value of Fourier coefficients for recorded cat, published tree shrew, and recorded squirrel. SE for squirrel is within thickness of line. There is a strong peak in cat V2 responses at $1 \mathrm{cycle} / \mathrm{mm}$ and a peak in tree shrew responses at 1.8 cycles/mm, corresponding to hypercolumn sizes of 1000 and $550 \mu \mathrm{m}$, respectively, and these values agree with hypercolumn sizes reported in the literature for these areas (Humphrey and Norton, 1980; Swindale et al., 1987; Bonhoeffer et al., 1995; Bosking et al., 1997). No peak is evident in squirrel V1 responses, suggesting no periodic organization. 


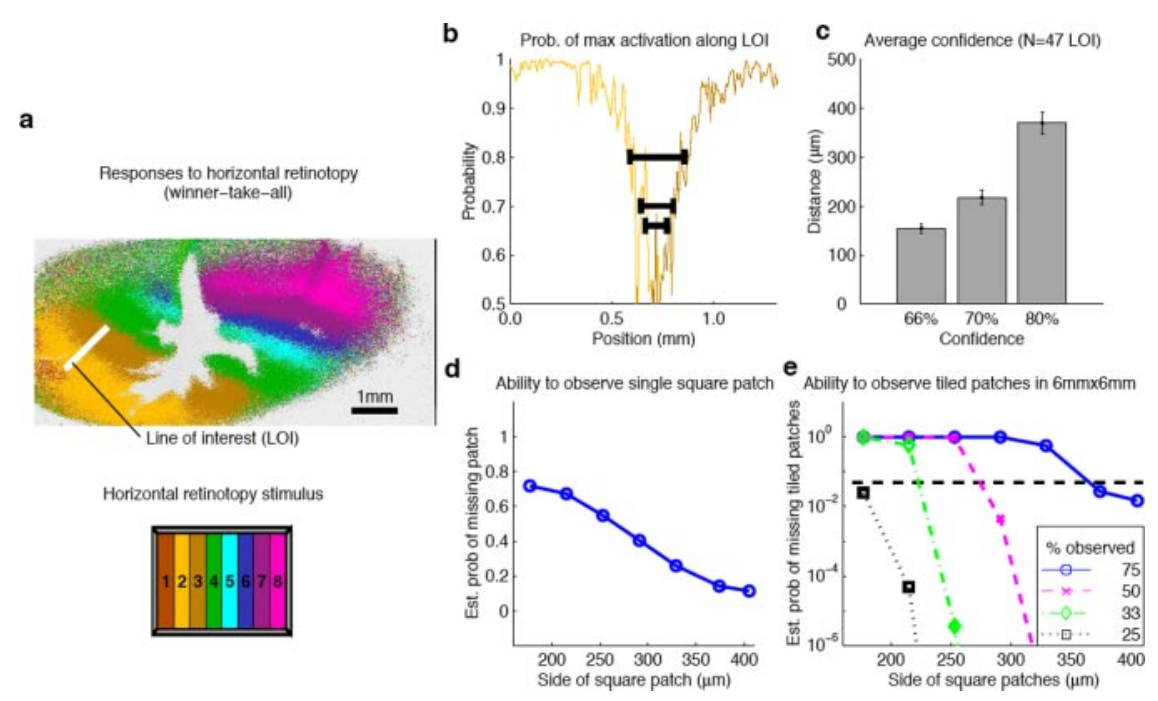

Figure 5. Upper limit of ability to image differentially activated groups of neurons. $a$, Winner-take-all image (top) of responses to horizontal retinotopy stimulus (bottom). $b$, Individual responses along an LOI connecting the areas of maximal response for stimulus 2 and stimulus 3 were used to simulate experiments to estimate the probability that stimulus 2 or 3 gave the maximum response for each pixel along the line. The width of the overlap region, or the uncertain region, was measured at several levels of confidence and corresponds to an upper bound of our ability to measure differential activity along a line connecting two points on the cortical surface. $c$, Mean \pm SE of overlap widths over 47 LOls for experiments in two animals. $d$, We used our confidence estimate for lines to construct an estimate of our ability to distinguish differentially activated square patches of different sizes. $e$, Estimated probability we would not observe minimum percentages of differentially activated square patches tiled in a $6 \times 6 \mathrm{~mm}$ image. For example, we estimate the probability we would fail to observe $>33 \%$ of tiled square patches with $253 \mu \mathrm{m}$ sides is 3.5e-6. Hypercolumns in tree shrews are $550 \mu \mathrm{m}$ wide (Humphrey and Norton, 1980; Bosking et al., 1997), so it is unlikely we would fail to identify structures of similar size in the squirrel if they existed.

Mean Fourier coefficients were calculated by mapping mean orientation angle responses at each pixel from the interval $0-180^{\circ}$ onto the interval $[-1,1]$, and computing the mean coefficients of the Fourier transform across each horizontal line in the image. Mean orientation angle responses for this analysis were determined by calculating the polar angle of responses to the four measured orientations. The mean values of Fourier coefficients at different spatial periods for the four squirrels and two cats we recorded and for published responses in tree shrew (Bosking et al., 1997) are shown in Figure 4 (bottom right). There is an obvious peak at $\sim 1$ cycle $/ \mathrm{mm}$ for the cat V2 data and a peak at 1.8 cycles/mm for the tree shrew V1 data, corresponding to hypercolumns of 1000 and $550 \mu \mathrm{m}$, respectively. These values agree with hypercolumn sizes reported in V2 of cat and V1 of tree shrew (Humphrey and Norton, 1980; Swindale et al., 1987; Bonhoeffer et al., 1995; Bosking et al., 1997). There is no similar peak in the squirrel Fourier coefficients, indicating a lack of periodicity in the squirrel orientation responses. The SE across the four squirrels is within the thickness of the line.

We tried several other plotting methods to identify orientation maps in squirrels. We tried normalizing individual responses by subtracting the average activity during the blank stimulus instead of subtracting the first frame of each stimulus as above, constructing winner-take-all maps using the response differences of orthogonal stimuli, and constructing smooth polar maps, but none of these suggested orientation maps in any squirrel (data not shown). In addition, we used a much more sensitive imaging paradigm as described by Kalatsky and Stryker (2003) that involves periodic stimulation and analysis of signal modulation at the stimulus frequency (see supplemental material, available at www.jneurosci.org). Consistent with the results above, we obtained robust retinotopic maps but found no maps of orientation selectivity (see supplemental Fig. 1, available at www.jneurosci.org as supplemental material).

\section{Upper bound imaging resolution estimate}

One possibility is that squirrels do have orientation maps, but our ability to image activity in distinct subpopulations of neurons is insufficient to see them. In addition to intrinsic noise in the system, including blurring of the hemodynamic signal through the camera and optics and trialto-trial variability in blood flow, many neurons in a small region may be nourished by the same vasculature and, thus, a region could show a strong hemodynamic response to two stimuli even if the same individual neurons are not activated by the two stimuli. Given this potential problem of broad measured activation to any particular stimulus, it is important to determine how well we can identify a spatially distinct area that shows a greater response to one stimulus compared with another stimulus. To explore our ability to resolve such areas, we estimated our ability to visually distinguish a square patch that was more strongly activated by one retinotopic stimulus from a neighboring patch more strongly activated by an adjacent retinotopic stimulus. We constructed this estimate by measuring our confidence in distinguishing one retinotopic stimulus from another adjacent stimulus along several lines of interest (LOIs) joining regions of maximum response to the two stimuli and used the line estimate to compute an estimate for a square patch. Because neurons with receptive fields at the border of two adjacent stimuli will be activated by both stimuli (Das and Gilbert, 1995; Toth et al., 1996), our line calculation is an upper bound, and our actual imaging resolution is finer than we estimate here.

We measured our confidence in distinguishing one retinotopic stimulus from another in four experiments in two animals. For this analysis, we showed gratings that randomly changed orientation in a thin vertical or horizontal rectangle on the screen. A line of interest drawn from the area of maximum activation by the second stimulus to the area of maximum activation by the third stimulus is shown in Figure $5 a$. To estimate our confidence in distinguishing one stimulus from another along this LOI, we computed the probability that each pixel was more strongly activated by one retinotopic stimulus than the adjacent stimulus (Fig. $5 b$ ). This probability was estimated by generating 10,000 simulated experiments of 20-26 trials based on the recorded data using the bootstrap method. We measured the width of the uncertain region for three levels of confidence for 47 lines over two experiments in two animals, and the results are shown in Figure $5 c$. We interpolated these points using a cubic spline to yield an estimate of our confidence in distinguishing two differentially activated points on the cortex as a function of the distance between them. For example, we would expect to distinguish points that are activated by different stimuli with $66 \%$ confidence if they were $152 \mu \mathrm{m}$ apart, and we would expect to distinguish differentially activated points with $80 \%$ confidence if they were $370 \mu \mathrm{m}$ apart. We then used this line estimate to calculate the likelihood 
of distinguishing square patches that are differentially activated by different stimuli. Each micrometer corresponded to 0.0816 pixels, and we assumed each square of size $M$ was composed of [ $M^{\star} 0.0816$ pixels/ $\mu \mathrm{m}$ ] lines of length $M$. We assumed the individual lines were measured independently and followed a binomial distribution with a probability of successful distinction equal to the line confidence. We assumed each patch would be visually identified successfully if $75 \%$ of the lines were successfully distinguished, and the likelihood that we would miss a patch is plotted for several patch sizes in Figure $5 d$. Finally, we computed the likelihood we would observe at least $75,50,33$, and $25 \%$ of tiled patches of equal sizes in our $6 \times 6$ $\mathrm{mm}$ viewing area, and this is plotted in Figure $5 e$. For example, if there were square patches with $177 \mu \mathrm{m}$ sides in our $6 \times 6$ $\mathrm{mm}$ viewing area, we estimate at worst case there is a probability of 0.025 that we would fail to observe at least $25 \%$ of the 1149 such square patches in the viewing area. The probability we would miss $>33 \%$ of square patches with $253 \mu \mathrm{m}$ sides is $3.5 \mathrm{e}-6$, and the probability we would miss $>50 \%$ of square patches with $291 \mu \mathrm{m}$ sides is 0.044 . Because the width of a hypercolumn is $\sim 550 \mu \mathrm{m}$ in tree shrew (Humphrey and Norton, 1980; Bosking et al., 1997), $570 \mu \mathrm{m}$ in monkey (Hubel et al., 1978), and 800-1200 $\mu \mathrm{m}$ in cat (Löwel et al., 1988), it is highly likely we would have observed evidence of structures of similar size in difference images from squirrel V1 if these structures existed.

\section{Orientation selectivity in single-unit recordings}

We examined the organization of orientation selectivity in 195 neurons under isoflurane anesthesia. Example responses and a histogram of orientation indices are shown in Figure $6 a-c$. The orientation index (OI) is defined as $\left[R_{\text {pref }}-R_{\text {orth }}\right] / R_{\text {pref }}$, where $R_{\text {pref }}$ and $R_{\text {orth }}$ are the responses to a stimulus of a preferred and orthogonal orientation, respectively, and nominally varies between 0 and 1 with values near one indicating high selectivity. The median orientation index was 0.72 . We assessed tuning width by measuring the HWHH. Two-thirds (133 of 195) of the cells had HWHH below $90^{\circ}$, which is a slightly lower fraction of tuned cells than reported in carnivores (e.g., 85\%) (Maldonado et al., 1997) and monkeys. The median half-width of these tuned cells was $28^{\circ}$, similar to carnivores (LeVay et al., 1987) and primates (O'Keefe et al., 1998; Ringach et al., 2002). Finally, we examined orientation-tuning width as a function of stimulus contrast. Figure $6 d$ shows orientation tuning curves for an example cell measured at 25,50 , and $75 \%$ contrast. HWHH for orientation tuning curves at 50 and $75 \%$ contrast for all cells with OI $>0.5$ is plotted in Figure $6 e$, and tuning widths seem relatively invariant to contrast in this species.

We also recorded 41 cells with urethane, the anesthetic used in the imaging experiments, to ensure that orientation tuning was not significantly different under urethane. Although the spontaneous rate was higher under urethane (median of 1.0 vs $0.3 \mathrm{~Hz}$ with isoflurane), the distributions of orientation indices were not b

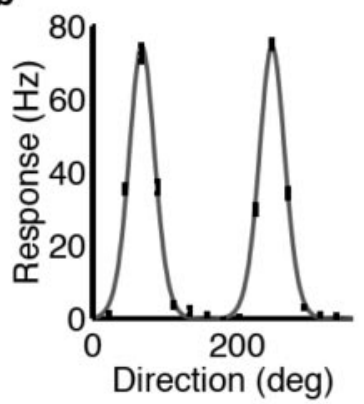

c
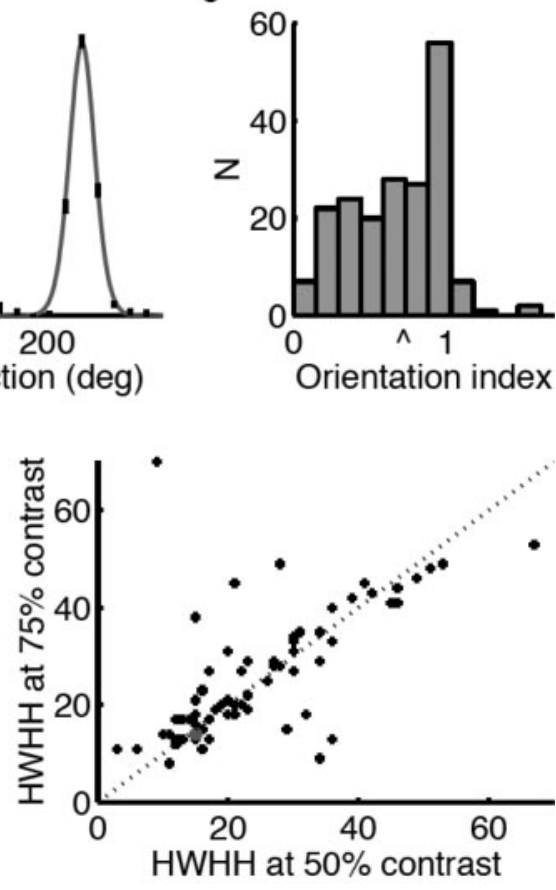

Figure 6. Orientation tuning in single-unit recordings in V1. $a$, Tuning of a complex cell with $0 \mathrm{I}=0.73$, the population median 列 response to 25,50 , and $75 \%$ stimulus contrast. $e$, The HWHH of all oriented cells with $\mathrm{HWHH}<70^{\circ}$ for stimulus contrast of 50 versus that at $75 \%$ contrast. The width is essentially invariant. The filled gray circle is the cell shown in $d$.

significantly different for the two anesthetics ( $p=0.5$; KruskalWallis test). The median OI was 0.69 under urethane.

\section{Clustering of orientation preference}

The orientation preference on most of our electrode penetrations showed no compelling evidence for columnar organization or a smooth map of orientation preference. Typically, orientation selectivity appeared to change randomly, as shown in Figure $7 a$, but on two penetrations of 20, we saw a hint of a more ordered map, as shown in Figure $7 b$. The median orientation index did not vary much across the 20 penetrations, and cells recorded during the two penetrations with a hint of order were no more or less oriented than cells recorded during other penetrations (KruskalWallis test; $p=0.76 ; p=0.67)$. There is clearly no columnar organization as striking as that reported previously in single-unit recordings in carnivores, tree shrew, and primates.

We also examined clustering of orientation preferences quantitatively. Figure $7 c$ shows the average difference in preferred orientation for sequentially recorded orientation-selective (OI $>0.67$ ) cells as a function of the distance between the cells. For cells within $100 \mu \mathrm{m}$ of each other, the average difference in preferred orientation is less than would be expected by chance $\left(45^{\circ}\right)$. In histology, we were able to estimate the angle of nine penetrations that were visible in a single brain slice, and the average deviation parallel to the plane of the slice was $11^{\circ}$ with an SD of $6.8^{\circ}$. If we assume an equal deviation perpendicular to the plane of section, our penetrations are on average $\sim 15^{\circ}$ to the surface normal, so we estimate that the maximum horizontal extent of a possible functional column of cells with similar orientation preferences is $\sim 30 \mu \mathrm{m}$. To determine whether there was a fast but orderly progression of the preferred orientation in single- 

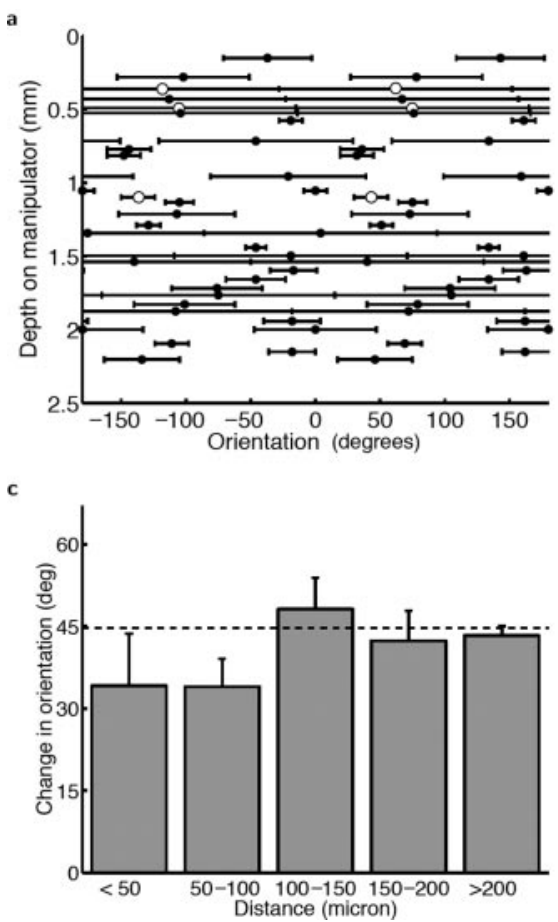

b

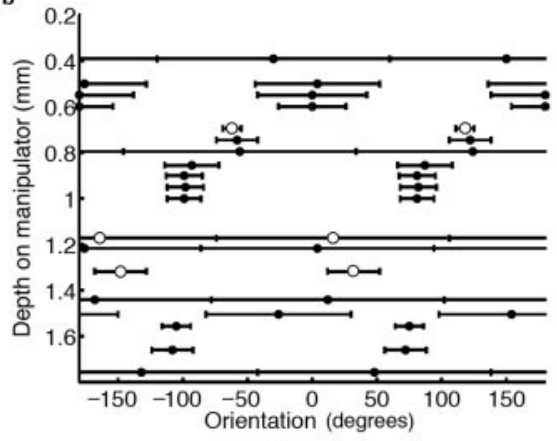

$d$

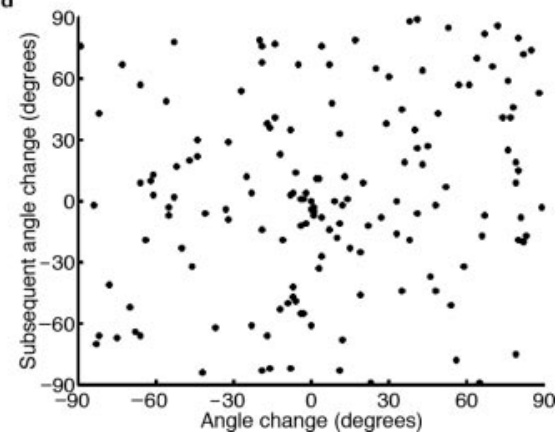

Figure 7. Clustering and lack of order in orientation preference. $a$, Typical example of change in orientation preference encountered during a single-electrode penetration. The orientation preference of each neuron is plotted twice, modulo $180^{\circ}$, to make it easier to visualize any structure. Closed circles are single isolated units; open circles are multiunits. Horizontal lines are twice half-width at half-height of maximum response. There is little evidence of smooth progression. $b$, One of only two penetrations of 20 where a hint of an ordered change in preferred orientation was seen. Penetrations were perpendicular to the surface to within $15^{\circ}$. c, Difference in preferred orientation angle between pairs of orientation-selective cells $(0 \mathrm{I}>0.66)$ recorded in the same penetration as a function of the distance between them. Error bars show mean $\pm \mathrm{SE}$. The dashed line at $45^{\circ}$ denotes value for a completely random distribution. $d$, Changes in preferred orientation angle between cells with an orientation bias $(0 \mathrm{l}>0.5)$ and the previous orientation-biased cell on the $x$-axis versus the change in orientation preference with the next orientation-biased cell encountered on an electrode penetration. There is a small correlation of 0.20 , caused by some large jumps. If only changes $<60^{\circ}$ are taken into account, there is no significant correlation, suggesting the absence of smooth progression.
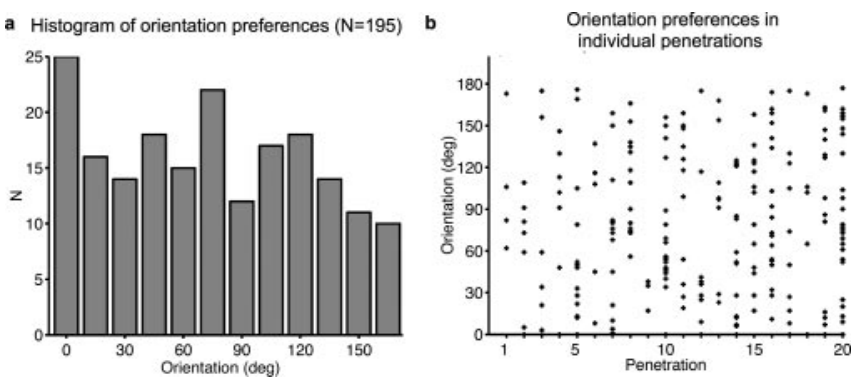

Figure 8. Little evidence for anisotropy in orientation preferences of squirrel V1 neurons. $a$, Histogram of orientation preference for $195 \mathrm{~V} 1$ neurons. Distribution is not different from uniform (Kolmogorov-Smirnov; $p=0.16$ ). $b$, Orientation preference of all neurons encountered in 20 individual vertical electrode penetrations. Only 4 of 20 penetrations showed differences from uniform (Kolmogorov-Smirnov; $p<0.05$ ), suggesting there is no dramatic local anisotropy of orientation preference at a given location in $\mathrm{V} 1$.

electrode penetrations, we plotted the change in preferred orientation between one pair of oriented cells and the change in the subsequent pair (i.e., one cell was in both pairs) in Figure $7 d$. For a slow progression through a smooth orientation map, one would expect all the points to lie close to the diagonal. The pairs of angle differences do show a small correlation of 0.20 , but this is entirely caused by large jumps (i.e., $>60^{\circ}$ ) increasing the likelihood that another large jump would be observed. If we only consider pairs with angle differences $<60^{\circ}$, the correlation disappears entirely, suggesting there is no smooth map.
Little anisotropy in orientation preferences

The mean responses to orientation stimuli in squirrel V1 measured by intrinsic imaging (Fig. 4) sometimes had large regions (several squared millimeters in area) that responded maximally to one particular orientation. This response might indicate a local anisotropy in orientation preferences: for example, maybe $50 \%$ of neurons in that region prefer one orientation, whereas the orientation preferences of the other $50 \%$ of the neurons are uniformly distributed. To examine this possibility, we computed the distribution of orientation preferences that we encountered in single-unit recordings for our entire population (Fig. 8a) and plotted orientation preferences for cells in each individual penetration (Fig. 8b). The distribution of orientation preferences across the entire population is not significantly different from uniform (Kolmogorov-Smirnov; $p=0.16)$. In addition, only 4 of 20 individual penetrations showed significant deviations from a uniform distribution $(5,7$, $9,12 ; p<0.05)$, suggesting that there are not strong local anisotropies in orientation preferences. Thus, whereas the responses in imaging might reflect slight anisotropies that we are unable to measure in single-unit recordings, we do not find evidence for large regions that prefer one orientation or large regions with dramatically skewed distributions of orientation preferences.

\section{Discussion}

We examined the organization of orientation selectivity in primary visual cortex of the gray squirrel using intrinsic signal imaging and single-unit recordings. Although we found robust retinotopic maps in imaging and many orientation-selective neurons in single-unit recordings, we found no evidence of orientation maps similar to those seen in primates, carnivores, and tree shrews. However, as in primates and carnivores (Sclar and Freeman, 1982; Skottun et al., 1987), orientation tuning in squirrels does not vary with stimulus contrast. Single-unit recordings revealed some evidence of very local clustering of cells with similar orientation preferences but no obvious columnar organization. We did not find evidence for local anisotropy of orientation preferences.

\section{Orientation maps in mammals}

One hypothesis for the lack of orientation maps in previously examined rodents and lagomorphs is the relatively poor differentiation of their visual systems, including poor acuity and contrast sensitivity and poorly laminated visual brain areas. High acuity, clear lamination, and orientation maps might all be hallmarks of a highly developed mammalian visual system that go hand in hand. Alternatively, animals such as rats and mice might have the capability to form orientation maps, but high quality visual input might be required for map expression. Squirrels have a highly elaborated and well-laminated lateral geniculate nucleus and V1 
Table 1. Comparison of adult weight, inverse magnification factor within $10^{\circ}$ of central vision, V1 surface area for one hemisphere, maximum acuity as measured by behavior, and orientation maps in V1 for several species

\begin{tabular}{|c|c|c|c|c|c|c|c|}
\hline Animal & Order & Adult weight & Magnification $^{-1}(\% / \mathrm{mm})$ & V1 area $\left(\mathrm{mm}^{2}\right)$ & Acuity $\left(\text { cycle } /{ }^{\circ}\right)^{b}$ & Eyes & Orientation maps \\
\hline Mouse & Rodentia & $25 \mathrm{gm}$ & $\sim 50$ & $2-3$ & 0.56 & Lateral & No \\
\hline Rat & Rodentia & $250 \mathrm{gm}$ & $\sim 25$ & 7 & 1.2 & Lateral & No \\
\hline Gray squirrel & Rodentia & $500-700 \mathrm{gm}$ & $3.5-4$ & $\sim 80^{a}$ & $2.8,3.9$ & Lateral & No \\
\hline Tree shrew & Scandentia & $100-300 \mathrm{gm}$ & $4-4.5$ & & 2.4 & Lateral & Yes \\
\hline Ferret & Carnivora & $800 \mathrm{gm}$ & 2.5 & $75-90$ & & Frontal & Yes \\
\hline Mink & Carnivora & $900 \mathrm{gm}$ & 5 & $\sim 100^{a}$ & 1.9 & Frontal & Yes \\
\hline Cat & Carnivora & $2.5-4 \mathrm{~kg}$ & 1.5 & 380 & 6.0 & Frontal & Yes \\
\hline Marmoset & Primates & $350 \mathrm{gm}$ & 0.73 & $192-217$ & & Frontal & Yes \\
\hline Owl monkey & Primates & $900 \mathrm{gm}$ & 1.25 & 275 & 10 & Frontal & Yes \\
\hline Macaque & Primates & $\sim 8 \mathrm{~kg}$ & 0.077 & 1325 & 46.0 & Frontal & Yes \\
\hline
\end{tabular}

Weight, inverse magnification factor, V1 size, and acuity do not predict the formation of orientation maps in mammals. The inverse magnification factor has been estimated linearly. Species and references are as follows: mouse, Mus sp. (Dräger, 1975; Prusky et al., 2000; Schuett et al., 2002); hooded rat, Rattus norvegicus (Espinoza and Thomas, 1983; Girman et al., 1999; Keller et al., 2000); mink, Mustela vision (Dustone et al., 1978; McConnell and LeVay, 1986; LeVay et al., 1987); tree shrew, Tupaia glis (Kaas et al., 1972; Petry et al., 1984; Bosking et al., 1997); squirrel, Sciurus carolinensis (Hall et al., 1971; Jacobs et al., 1982); ferret, Mustela furo (Law et al., 1988; Rao et al., 1997), cat, Felis domesticus (Hubel and Wiesel, 1963; Blake et al., 1974; LeVay and Gilbert, 1976; Tusa et al., 1978), marmoset, Callithrix jacchus (Fritsches and Rosa, 1996; Liu and Pettigrew, 2003); owl monkey, Aotus trivirgatus (Allman and Kaas, 1971; Jacobs, 1977; Sereno et al., 1995); macaque monkey, Macaca mulatta (Hubel et al., 1978; Tootell et al., 1982; Sereno et al., 1995).

${ }^{a}$ Value not explicitly reported but estimated from figures and equations in the studies cited.

${ }^{b}$ Mean luminance (in cd/ $/ \mathrm{m}^{2}$ ): mouse, 43; rat, 51; gray squirrel, 3.4 and 340; tree shrew, 35; mink, 108; cat, 17.1; owl monkey, 11.4; macaque, 17.1.

and at least four large extrastriate visual areas and show much clearer laminar organization in V1 and V2 compared with other rodents (Hall et al., 1971). LGN, superior colliculus, and pulvinar in squirrel are very similar in size, lamination, and connections to those found in tree shrews (Diamond, 1976). Furthermore, behaviorally measured acuity (Table 1) in squirrels (Jacobs et al., 1982) is slightly superior to that of the tree shrew (Petry et al., 1984) and mink (Dunstone and Sinclair, 1978). The fact that squirrels lack orientation maps suggests that well-defined visual brain structures and high acuity and contrast sensitivity are neither sufficient for nor dependent on the development of orientation maps in mammals.

A second hypothesis for the lack of orientation maps in rodents is the small absolute V1 size of the studied species. Orientation maps might form in animals with larger visual cortices so cells with similar orientation preferences could make local connections more easily, and orientation maps might not be necessary in animals with smaller visual cortices, because synaptic connections among cells with similar orientations could be made easily without any additional organization. Two pieces of data argue against this view. First, V1 in squirrels is larger and shows slightly more magnification in the first $10^{\circ}$ of vision than V1 in the tree shrew and is comparable with ferret (Table 1), yet tree shrew and ferret both show robust orientation maps (Humphrey and Norton, 1980; Bosking et al., 1997; Rao et al., 1997), whereas squirrels do not. Second, in the far periphery, most animals in Table 1 show much less cortical magnification than they do in the visual field center, e.g., $24^{\circ} \mathrm{mm}$ in cat (McConnell and LeVay, 1986), yet orientation maps exist throughout the entire V1 representation (Löwel et al., 1988).

\section{Columnar organization}

Columnar organization, or invariance of some functional properties across layers, has been observed in many cortical regions (Mountcastle, 1997), and all mammals examined to date seem to have a columnar organization for receptive field location in V1 (Kaas, 1997). Given that rodents do not have orientation maps, do they have such a columnar organization for orientation? Many investigators believe there is an anatomical substrate for functional columns, and histological studies in rodents, rabbits, cats, and monkeys have detected small columns with a diameter of the order of $50 \mu \mathrm{m}$ (Mountcastle, 1997). Our single-unit recordings suggest that if the orientation preference is organized in columns in squirrels, they must be very small, not $>30 \mu \mathrm{m}$ across.

In tree shrews (Bosking et al., 1997) and cats (Gilbert and Wiesel, 1989), orientation-selective cells in V1 make long-range (1-2 mm) axonal connections that ramify in patches of cortex with similar orientation preferences. Squirrels do have longrange intrinsic connections, and these connections have a modestly patchy organization (Kaas et al., 1989), but it is unclear which groups of neurons are connected. These connections might link functional modules unrelated to orientation preference. A second possibility is that these long-range connections do link neurons with similar orientation preferences; the patches could correspond to very small clusters of cells with similar orientations, or perhaps within each patch there are neurons with many orientation preferences, and only neurons with similar orientation preferences are actually connected. Finally, these longrange connections may not link neurons with similar properties in the squirrel and may serve some other function.

\section{Functional implications}

The absence of an orientation map in the highly visual gray squirrel begs the question of what functional role the map plays in animals that do possess it. Some models of V1 posit that orientation selectivity and selectivity that is invariant to stimulus contrast arise from local synaptic connections, with neurons receiving a large excitatory input from nearby cells with similar orientation preferences and broadly tuned inhibition (BenYishai et al., 1995; Somers et al., 1995). However, rodents and lagomorphs do show robust orientation tuning in V1 (Murphy and Berman, 1979; Girman et al., 1999), despite lacking an orientation map, and we have shown that orientation tuning in squirrels is contrast invariant. In addition, V1 is essential for the perception of orientation in squirrels, because V1 lesions in ground squirrels impair orientation discrimination (Kicliter et al., 1977). Thus, it is likely that orientation maps are not important or necessary for orientation tuning or contrast invariance of orientation tuning. It is still possible, however, that orientation maps do enable some richer computations in animals that have them; for example, modulation by the receptive field surround may be different in squirrel than in tree shrew, cat, and monkey.

In a recent intracellular study, Schummers et al. (2002) found that subthreshold inputs to cat V1 neurons varied as a function of 
the location of the cell within the orientation map. Although spike output of all cells was highly tuned, cells in smoothly varying regions (iso-orientation domains) received highly orientation-tuned input, but cells near singularities (pinwheel centers) received broadly tuned input. Given that squirrels do not have an orientation map, it will be interesting to see whether functional input to squirrel V1 cells is highly tuned, broadly tuned, or variable.

Koulakov and Chklovskii (2001) suggest that each animal possesses mechanisms that minimize the wiring length of connections in V1. According to their model, animals for which neurons with similar orientations are connected, the minimal solution is a smooth orientation map with pinwheel structure, and in animals with less orientation-specific connections, there is no map. It remains to be seen whether rodents have different connectivity profiles with respect to orientation than other mammals.

Another theory is that smooth organization maximizes the uniformity of coverage of receptive field properties (Swindale et al., 2000). Requiring continuity of receptive field properties along the cortical surfaces could help in ensuring adequate local encoding of all stimulus properties (e.g., orientation preference, spatial frequency preference, etc.). It seems unlikely that orientation maps are required for this purpose, however, as a highly visual animal like squirrel must have some mechanism to maximize coverage.

Finally, it is possible that orientation maps are an epiphenomenal product of development and play no important role in vision (Purves et al., 1992).

\section{Developmental modeling}

Many developmental models of orientation maps posit a fixed, Mexican hat-type of intracortical connections with local excitation and longer-range inhibition (Erwin et al., 1995; Miller et al., 1999). Combined with Hebbian plasticity, such schemes naturally create a smooth map. It also has been hypothesized that inhomogeneities (Ernst et al., 2001) or anisotropies (Adorjan et al., 1999) in these intracortical connections create the orientation selectivity and map even without activity-dependent plasticity. In all of these models, the spatial correlation length is determined by the strength and arbor widths of the local excitatory and inhibitory connections, so if they correctly describe orientation map formation, V1 connectivity in rodents must be much different from primates, carnivores, and tree shrews.

Many species have 1-2 mm horizontal projections in V1 that connect neurons with similar orientation preferences (Gilbert and Wiesel, 1989; Bosking et al., 1997). Some investigators have suggested that these long-range connections, which are present before orientation maps developmentally, could be a framework underlying the creation of orientation maps (Katz and Callaway, 1991; Ruthazer and Stryker, 1996; Shouval et al., 2000). However, anatomical studies of squirrels (Kaas et al., 1989) have shown that these animals also have long-range 1-2 mm connections in V1, so the role of these connections in map formation remains unclear.

\section{Functional architecture in cortex}

What features of sensory cortex are universal, and which vary from species to species? All mammalian primary cortical sensory areas examined to date have a topographic representation of the sensory receptors (Kaas, 1997). Our data suggest that modular, orderly maps of functional receptive field properties are not a universal feature of mammalian V1. The functional architecture of ocular dominance bands in V1 also shows great heterogeneity, with Old World monkeys and some carnivores showing distinct, alternating bands of input from the two eyes but with many New World monkeys, sheep, rodents, and rabbits showing no alternating bands (Livingstone, 1986; LeVay and Nelson, 1991; Adams and Horton, 2003). Detailed comparisons of functional properties are not available for many species in somatosensory cortex, but anatomical properties vary widely. Some rodents and marsupials show specialized rings of high- or low-cell density and thalamic input ("barrels") in regions mediating responses from the mystacial vibrissae, whereas others do not, and the existence of these structures is not predicted by brain size or whether the animal actively uses the vibrissae for exploration (Woolsey et al., 1975). Thus, whereas topographic representation of sensory receptors appears to be a general feature of mammalian sensory cortex, organization of other functional properties may vary considerably from species to species. Recent advances in genome sequencing and genetic experimental techniques may allow genetic bases of these differences to be uncovered.

\section{References}

Adams DL, Horton JC (2003) Capricious expression of cortical columns in the primate brain. Nat Neurosci 6:113-114.

Adorjan P, Levitt JB, Lund JS, Obermayer KA (1999) Model for the intracortical origin of orientation preference and tuning in macaque striate cortex. Vis Neurosci 16:303-318.

Allman JM, Kaas JH (1971) Representation of the visual field in striate and adjoining cortex of the owl monkey (Aotus trivirgatus). Brain Res 35:89-106.

Ben-Yishai R, Bar-Or RL, Sompolinsky H (1995) Theory of orientation tuning in visual cortex. Proc Natl Acad Sci USA 92:3844-3848.

Blake R, Cool SJ, Crawford ML (1974) Visual resolution in the cat. Vision Res 14:1211-1217.

Blasdel GG, Salama G (1986) Voltage-sensitive dyes reveal a modular organization in monkey striate cortex. Nature 321:579-585.

Bonhoeffer T, Kim DS, Malonek D, Shoham D, Grinvald A (1995) Optical imaging of the layout of functional domains in area 17 and across the area 17/18 border in cat visual cortex. Eur J Neurosci 7:1973-1988.

Bosking WH, Zhang Y, Schofield B, Fitzpatrick D (1997) Orientation selectivity and the arrangement of horizontal connections in tree shrew striate cortex. J Neurosci 15:2112-2127.

Brainard DH (1997) The psychophysics toolbox. Spat Vis 10:433-436.

Clarke PG, Donaldson IM, Whitteridge D (1976) Binocular visual mechanisms in cortical areas I and II of the sheep. J Physiol (Lond) 256:509-526.

Das A, Gilbert CD (1995) Long-range horizontal connections and their role in cortical reorganization revealed by optical recording of cat primary visual cortex. Nature 375:780-784.

Diamond IT (1976) Organization of the visual cortex: comparative anatomical and behavioral studies. Fed Proc 35:60-67.

Dräger UC (1975) Receptive fields of single cells and topography in mouse visual cortex. J Comp Neurol 160:269-290.

Dunstone N, Sinclair W (1978) Comparative aerial and underwater visual acuity of the mink, Mustela vison schreber, as a function of discrimination distance and stimulus luminance. Anim Behav 26:6-13.

Ernst UA, Pawelzik KR, Sahar-Pikielny C, Tsodyks MV (2001) Intracortical origin of visual maps. Nat Neurosci 4:431-436.

Erwin E, Obermayer K, Schulten K (1995) Models of orientation and ocular dominance columns in the visual cortex: a critical comparison. Neural Comput 7:425-468.

Espinoza SG, Thomas HC (1983) Retinotopic organization of striate and extrastriate visual cortex in the hooded rat. Brain Res 272:137-144.

Fritsches KA, Rosa MG (1996) Visuotopic organisation of striate cortex in the marmoset monkey (Callithrix jacchus). J Comp Neurol 372:264-282.

Gilbert CD, Wiesel TN (1989) Columnar specificity of intrinsic horizontal and corticocortical connections in cat visual cortex. J Neurosci 9:2432-2442.

Girman SV, Sauve Y, Lund RD (1999) Receptive field properties of single neurons in rat primary visual cortex. J Neurophysiol 82:301-311.

Grinvald A, Lieke E, Frostig RD, Gilbert CD, Wiesel TN (1986) Functional architecture of cortex revealed by optical imaging of intrinsic signals. Nature 324:361-364.

Hall WC, Kaas JH, Killackey H, Diamond IT (1971) Cortical visual areas in 
the grey squirrel (Sciurus carolinensis): a correlation between cortical evoked potential maps and architectonic subdivisions. J Neurophysiol 34:437-452.

Hubel DH, Wiesel TN (1962) Receptive fields, binocular interaction and functional architecture in the cat's visual cortex. J Physiol (Lond) 160:106-154.

Hubel DH, Wiesel TN (1963) Shape and arrangement of columns in cat's striate cortex. J Physiol (Lond) 165:559-568.

Hubel DH, Wiesel TN, Stryker MP (1978) Anatomical demonstration of orientation columns in macaque monkey. J Comp Neurol 177:361-380.

Humphrey AL, Norton TT (1980) Topographic organization of the orientation column system in the striate cortex of the tree shrew (Tupaia glis). I. Microelectrode recording. J Comp Neurol 192:531-547.

Jacobs GH (1977) Visual capacities of the owl monkey (Aotus trivirgatus). II. Spatial contrast sensitivity. Vision Res 17:821-825.

Jacobs GH, Birch DG, Blakeslee B (1982) Visual acuity and spatial contrast sensitivity in tree squirrels. Behav Proc 7:367-375.

Kaas JH (1997) Topographic maps are fundamental to sensory processing. Brain Res Bull 44:107-112.

Kaas JH, Hall WC, Killackey H, Diamond IT (1972) Visual cortex of the tree shrew (Tupaia glis): architectonic subdivisions and representations of the visual field. Brain Res 42:491-496.

Kaas JH, Krubitzer LA, Johanson KL (1989) Cortical connections of areas 17 (V-I) and 18 (V-II) of squirrels. J Comp Neurol 281:426-446.

Kalatsky VA, Stryker MP (2003) New paradigm for optical imaging: temporally encoded maps of intrinsic signal. Neuron 38:529-545.

Katz LC, Callaway EM (1991) Emergence and refinement of local circuits in cat striate cortex. In: Development of the visual system (Lam DM-K, Shatz CJ, eds), pp 197-216. Cambridge, MA: MIT.

Keller J, Strasburger H, Cerutti DT, Sabel BA (2000) Assessing spatial vision-automated measurement of the contrast-sensitivity function in the hooded rat. J Neurosci Methods 15:103-110.

Kicliter E, Loop MS, Jane JA (1977) Effects of posterior neocortical lesions on wavelength, light/dark and stripe orientation discrimination in ground squirrels. Brain Res 122:15-31.

Koulakov AA, Chklovskii DB (2001) Orientation preference patterns in mammalian visual cortex: a wire length minimization approach. Neuron 29:316-317.

Law MI, Zahs KR, Stryker MP (1988) Organization of primary visual cortex (area 17) in the ferret. J Comp Neurol 278:157-180.

LeVay S, Gilbert CD (1976) Laminar patterns of geniculocortical projection in the cat. Brain Res 113:1-19.

LeVay S, Nelson SB (1991) Columnar organization of the visual cortex. In: The neural basis of visual function (Leventhal AG, ed), pp 266-315. London: Macmillan.

LeVay S, McConnell SK, Luskin MB (1987) Functional organization of primary visual cortex in the mink (Mustela vision), and a comparison with the cat. J Comp Neurol 257:422-441.

Liu GB, Pettigrew JD (2003) Orientation mosaic in barn owl's visual Wulst revealed by optical imaging: comparison with cat and monkey striate and extra-striate areas. Brain Res 961:153-158.

Livingstone MS (1986) Ocular dominance columns in New World monkeys. J Neurosci 16:2086-2096.

Löwel S, Bischof H-J, Leutenecker B, Singer W (1988) Topographic relations between ocular dominance and orientation columns in the cat striate cortex. Exp Brain Res 71:33-46.

Maldonado PE, Godecke I, Gray CM, Bonhoeffer T (1997) Orientation selectivity in pinwheel centers in cat striate cortex. Science 276:1551-1555.

McConnell SK, LeVay S (1986) Anatomical organization of the visual system of the mink, Mustela vision. J Comp Neurol 250:109-132.

Metin C, Godement P, Imbert M (1988) The primary visual cortex in the mouse: receptive field properties and functional organization. Exp Brain Res 69:594-612.

Miller KD, Erwin E, Kayser A (1999) Is the development of orientation selectivity instructed by activity? J Neurobiology 41:44-57.
Mountcastle VB (1997) The columnar organization of the neocortex. Brain 120:701-722.

Murphy EH, Berman N (1979) The rabbit and the cat: a comparison of some features of response properties of single cells in the primary visual cortex. J Comp Neurol 188:401-427.

O’Keefe LP, Levitt JB, Kiper DC, Shapley RM, Movshon JA (1998) Functional organization of owl monkey lateral geniculate nucleus and visual cortex. J Neurophysiol 80:594-609.

Pelli DG (1997) The VideoToolbox software for visual psychophysics: transforming numbers into movies. Spat Vis 10:437-442.

Petry HM, Fox R, Casagrande VA (1984) Spatial contrast sensitivity of the tree shrew. Vision Res 24:1037-1042.

Press WH, Flannery BP, Teukolsky SA, Vetterling WT (1993) Numerical recipes in C. Cambridge: Cambridge UP.

Prusky GT, Reidel C, Douglas RM (2000) Environmental enrichment from birth enhances visual acuity but not place learning in mice. Behav Brain Res 114:11-15.

Purves D, Riddle DR, LaMantia AS (1992) Iterated patterns of brain circuitry (or how the cortex gets its spots). Trends Neurosci 15:362-368.

Rao SC, Toth LJ, Sur M (1997) Optically imaged maps of orientation preference in primary visual cortex of cats and ferrets. J Comp Neurol 387:358-370.

Ringach DL, Shapley RM, Hawken MJ (2002) Orientation selectivity in macaque V1: diversity and laminar dependence. J Neurosci 22:5639-5651.

Ruthazer ES, Stryker MP (1996) The role of activity in the development of long-range horizontal connections in area 17 of the ferret. J Neurosci 16:7253-7269.

Schuett S, Bonhoeffer T, Hübener M (2002) Mapping retinotopic structure in mouse visual cortex with optical imaging. J Neurosci 22:6549-6559.

Schummers J, Marino J, Sur M (2002) Synaptic integration by V1 neurons depends on location within the orientation map. Neuron 36:969-978.

Sclar G, Freeman RD (1982) Orientation selectivity in the cat's striate cortex is invariant with stimulus contrast. Exp Brain Res 46:457-461.

Sereno MI, Dale AM, Reppas JB, Kwong KK, Belliveau JW, Brady TJ, Rosen BR, Tootell RB (1995) Borders of multiple visual areas in humans revealed by functional magnetic resonance imaging. Science 268:889-893.

Shouval HZ, Goldberg DH, Jones JP, Beckerman M, Cooper LN (2000) Structured long-range connections can provide a scaffold for orientation maps. J Neurosci 20:1119-1128.

Skottun BC, Bradley A, Sclar G, Ohzawa I, Freeman RD (1987) The effects of contrast on visual orientation tuning in cat visual cortex. J Neurophysiol 57:773-786.

Snodderly DM, Gur M (1995) Organization of striate cortex of alert, trained monkeys (Macaca fascicularis): ongoing activity, stimulus selectivity, and widths of receptive field activating regions. J Neurophysiol 74:2100-2125.

Somers DC, Nelson SB, Sur M (1995) An emergent model of orientation selectivity in cat visual cortical simple cells. J Neurosci 15:5448-5465.

Swindale NV, Matsubara JA, Cynader MS (1987) Surface organization of orientation and direction selectivity in cat area 18. J Neurosci 7:1414-1427.

Swindale NV, Shoham D, Grinvald A, Bonhoeffer T, Hubener M (2000) Visual cortex maps are optimized for uniform coverage. Nat Neurosci 3:822-826.

Tiao YC, Blakemore C (1976) Functional organization in the visual cortex of the golden hamster. J Comp Neurol 168:459-481.

Toth LJ, Rao SC, Kim DS, Somers D, Sur M (1996) Subthreshold facilitation and suppression in primary visual cortex revealed by intrinsic signal imaging. Proc Natl Acad Sci USA 93:9869-9874.

Tusa RJ, Palmer LA, Rosenquist AC (1978) The retinotopic organization of area 17 (striate cortex) in the cat. J Comp Neurol 177:213-236.

Van Hooser SD, Heimel JAF, Nelson SB (2003) Receptive field properties and laminar organization of lateral geniculate nucleus in the gray squirrel (Sciurus carolinensis). J Neurophysiol 90:3398-3418.

Woolsey TA, Welker C, Schwartz RH (1975) Comparative anatomical studies of the SmL face cortex with special reference to the occurrence of "barrels" in layer IV. J Comp Neurol 164:79-94. 